\title{
Filiação Industrial e Diferencial de Salários no Brasil*
}

\author{
Jorge Saba Arbache** \\ João Alberto De Negri ${ }^{* * *}$
}

Sumário: 1. Introdução; 2. Teoria e evidência; 3. Metodologia e dados; 4. Resultados; 5. Conclusões.

Palavras-chave: diferencial de salários inter-industriais; determinação de salários; Brasil.

Códigos JEL: J31.

Este artigo investiga os diferenciais de salários inter-industriais no Brasil. Os efeitos da filiação industrial nos salários foram examinados ao nível de três dígitos, e foram utilizadas variáveis de controle associadas às firmas como tamanho das plantas, nacionalidade do capital e acesso ao mercado internacional, além de variáveis associadas aos trabalhadores. Dessa forma, foi possível a estimação dos prêmios salariais industriais considerando tanto características da oferta como, também, da demanda de trabalho. Encontraram-se evidências de que valor adicionado, margem de lucro e tecnologia ao nível da indústria afetam o diferencial de salários no Brasil.

This paper investigates the inter-industry wage differentials in Brazil. We examine the impacts of industry affiliation at the three-digit level, and control our regressions with firm variables such as plant size, nationality of capital, and international trade, among several labor variables. Therefore, we could access the impact of industry affiliation on wages taking into account supply and demand characteristics. We found evidence that value added, profits and technology at the industry level affect the wage dispersion in Brazil.

\section{Introdução}

Um dos mais intrigantes tópicos em economia é o diferencial de salários interindustriais. Economistas encontram elevada regularidade da dispersão salarial

\footnotetext{
*Artigo recebido em abr. 2003 e aprovado em fev. 2004. Agradecemos os comentários e sugestões de Gustavo Gonzaga e dos participantes do II Seminário de Economia Aplicada UnB/IPEA/MTE, ANPEC 2002 e Universidade Católica de Brasília. Os erros e imprecisões são, naturalmente, nossos. Arbache é financiado pelo CNPq, a quem gostaria de agradecer.

${ }^{* *}$ Universidade de Brasília

${ }^{* * *}$ IPEA
} 
entre e intra-indústrias para diferentes países, mesmo após controlar para diferentes atributos dos indivíduos, firmas e indústrias (Krueger e Summers, 1987, 1988; Gittleman e Wolf, 1993, inter alia). Esses resultados sugerem que os diferenciais de salários são compatíveis com o funcionamento das economias de mercado e levantam dúvidas sobre a adequação das teorias competitivas para explicar a dispersão de salários.

No Brasil, a investigação das causas do diferencial de salários tem particular relevância devido à elevada concentração da renda (Langoni, 1973, Bacha e Taylor, 1978, Cowell et alii, 1996, Ferreira e Barros, 1999). Identificar se e como a filiação industrial contribui para a formação e dispersão de salários pode ser fundamental para o conhecimento das características dos mercados de trabalho e de bens e para o desenho de políticas públicas, especialmente as que visam reduzir a desigualdade.

Este artigo oferece novos elementos para a análise do diferencial de salários industriais no Brasil. O trabalho tem três contribuições. Primeira, investiga o diferencial de salários industriais ao nível de três dígitos. Segunda, as equações de salários controlam não apenas as características dos trabalhadores, mas, também, das firmas a que estes estão filiados. Terceira, examina os determinantes dos prêmios salariais inter-industriais.

O banco de dados que utilizamos é inédito e resulta da junção dos micro-dados do Relatório Anual de Informações Sociais (RAIS), do Ministério do Trabalho e Emprego, Pesquisa Industrial Anual (PIA), do Instituto Brasileiro de Geografia e Estatística (IBGE), registros de importação e exportação da Secretaria de Comércio Exterior (SECEX-MDIC), e Censo de Capital Estrangeiro do Banco Central do Brasil. O banco de dados e a metodologia utilizada permitiram tratar os potenciais problemas que a agregação da classificação industrial a um ou dois dígitos e a ausência de características das firmas podem trazer para as estimativas dos prêmios salariais e sua dispersão.

O artigo está organizado como segue: a seção 2 apresenta considerações teóricas e empíricas sobre o diferencial de salários industriais. A seção 3 discute a estratégia econométrica e apresenta os dados utilizados. A seção 4 apresenta e discute os resultados empíricos. A seção 5 conclui.

\section{Teoria e Evidência}

O objetivo mais comum da literatura de diferencial de salários é testar a hipótese da lei de um preço para a determinação de salários. A hipótese examinada é que em um mercado de trabalho competitivo trabalhadores com iguais características devem ganhar salários iguais, e que filiação industrial não afeta a 
determinação de salários. Nesse caso, a dispersão de salários industriais deve ser muito pequena ou próxima a zero, já que, em princípio, não há porque se esperar que um empregador pague mais que o salário de mercado para trabalhadores com características produtivas similares. As eventuais diferenças de salários seriam resultado de diferenças nas características dos trabalhadores, condições de trabalho, ocupação, etc., mas não da filiação industrial.

Embora a teoria do capital humano seja bastante popular para explicar a dispersão de salários, características produtivas individuais e ocupacionais não têm sido capazes de justificar mais que parte da dispersão salarial. Teorias alternativas de determinação de salário abundaram nas últimas duas décadas com o objetivo de explicar o persistente diferencial de salários. Uma boa teoria de determinação de salário, no entanto, tem que ser capaz de justificar porque um empregador paga mais para um trabalhador que, em princípio, poderia ser substituído por outro trabalhador ganhando um salário menor.

Não há como classificar as teorias de diferencial de salários por ordem de importância, já que uma teoria pode ser mais adequada que outra para explicar fenômenos de mercados de trabalho específicos. Além do mais, como os fenômenos do mercado de trabalho são mutáveis - porque a organização social e econômica muda com o tempo, bem como é influenciada pelas instituições e pela cultura, as quais estão em constante transformação - uma teoria relevante para explicar um fenômeno em um determinado período pode não sê-lo para explicar em outro período e/ou contexto.

Nas décadas recentes, a teoria da segmentação do mercado de trabalho tornouse um campo de intensa investigação tendo como um dos objetivos a explicação de problemas como a dispersão de salários. Diferentes fatores têm sido identificados como fonte de segmentação, como filiação industrial, sindicatos, concentração de mercado, regulamentação do mercado de trabalho, dentre outros. No entanto, mesmo antes do crescimento da literatura de segmentação a partir da década de 1970 a filiação industrial já era apontada como fonte de diferencial dos salários (Slichter, 1950, Reynolds, 1951, Cullen, 1956, Dunlop, 1957, Wachter, 1970). Mais recentemente, um vasto número de trabalhos confirmou que filiação industrial é importante causa de dispersão de salários para países com diferentes estágios de desenvolvimento e diferentes tipos de instituições que governam o mercado de trabalho (Dickens e Katz, 1987, Krueger e Summers, 1987, 1988, Gittleman e Wolff, 1993, Abuhadba e Romaguera, 1993, Arbache, 2001), inter alia. Essa literatura enfatiza que características industriais como concentração, razão capital/trabalho, taxa de lucro e densidade sindical têm forte impacto na determinação de salários mudando a perspectiva de análise do lado do trabalhador para o lado da indústria. 
Um argumento para explicar a relação entre concentração, lucros e diferencial de salários industriais refere-se ao custo de greves e outros tipos de manifestações que afetam o ritmo normal das operações produtivas das firmas de mercados concentrados, que seriam mais lucrativas devido às rendas de monopólio. Adicionalmente, a firma prefere pagar maiores salários para evitar a sindicalização dos trabalhadores e a interferência dos sindicatos nas negociações salariais (Dickens, 1986). Trabalhadores filiados às indústrias que adotam tecnologias mais sofisticadas também pagariam maiores salários. A idéia é que existe elevada complementaridade entre capital e trabalho nesses setores, e que a rotatividade do trabalho afeta o ritmo de produção, incentivando a indústria a pagar melhores salários para reter seus trabalhadores.

Com o desenvolvimento dos modelos de salários de eficiência na década de 1980, nova ênfase foi colocada na filiação industrial como fonte de diferencial de salários, mas, agora, através de modelos que explicavam a racionalidade econômica da segmentação. Esses modelos propõem a ligação entre as características da firma e indústria e a formação de salários, e incorporam vários aspectos da teoria competitiva. Os modelos mostram que o diferencial de salários pode resultar de um equilíbrio ótimo (para um survey, veja Weiss (1990)).

Recentemente, a pesquisa de diferenciais de salários industriais tem se concentrado em tentativas de confrontar as teorias competitivas com as teorias de salários de eficiência (Krueger e Summers, 1988, Katz e Summers, 1989b,a, Murphy e Topel, 1990, Lucifora, 1993, Gera e Grenier, 1994, Arai, 1994, Arbache, 2001). ${ }^{1}$ Os resultados empíricos mais comuns são: variáveis de controle do indivíduo e da firma não são suficientes para explicar todo o diferencial de salários; os diferenciais de salários inter-industriais são persistentes ao longo do tempo; elevada correlação entre prêmio salarial por ocupação e firmas de diferentes tamanhos e características de uma mesma indústria; modelos de salários de eficiência explicam ao menos parte do diferencial de salários; e certas indústrias pagam altos (baixos) salários para todos os trabalhadores, desde diretores a trabalhadores não qualificados. A conclusão básica dessa literatura é que a filiação industrial é fonte fundamental de explicação da dispersão salarial. ${ }^{2}$

No caso de países em desenvolvimento, a filiação industrial tem contornos adicionais devido às características dos mercados de trabalho desses países. A

\footnotetext{
${ }^{1}$ Ver Groshen (1991a,b) para uma extensão da análise para o diferencial de salários intraindústria.

${ }^{2}$ Outras teorias usualmente examinadas para os diferenciais de salários industriais são rentsharing, modelos de barganha e habilidades não mensuradas (Blanchflower et alii, 1996, DiNardo et alii, 1996, Keane, 1993, Abowd et alii, 1999). Para uma análise da teoria de rent-sharing para o Brasil, ver Menezes-Filho e Arbache (2003).
} 
questão do status legal do contrato de trabalho, nacionalidade do capital da firma e se esta é exportadora são elementos que podem contribuir substancialmente para explicar a formação salarial (Souza e Tokman, 1978, Lindauer e Sabot, 1983, Fields e Wan, 1989, Teal, 1996, Morrison, 1994).

Apresenta-se brevemente a seguir uma seleção de estudos que tratam de filiação industrial e diferencial de salários no Brasil. Alguns dos estudos investigam apenas indiretamente o efeito da indústria no diferencial de salários, enquanto outros analisam com mais detalhes os diferenciais de salários industriais.

Cunha e Bonelli (1978) estimam e decompõem equações de salários usando o Censo Populacional de 1970. Eles encontram que as características industriais são os mais importantes fatores para explicar a determinação de salários.

Da Silva (1987) investiga os determinantes do diferencial de salários utilizando os dados da RAIS de 1977 e os arquivos de imposto de renda das firmas de 1978 da Secretaria da Receita Federal. Ele encontra que características da firma como tamanho, produtividade, lucratividade, medidas de mercados internos de trabalho, desempenho do setor, medidas de grau de concentração setorial e sindicalização têm importante impacto na formação dos salários, embora as medidas de capital humano tenham se mostrado como as mais relevantes para explicar a dispersão dos salários.

Cacciamali e Freitas (1991) examinam a determinação de salários na região metropolitana de São Paulo utilizando dados da RAIS de 1987 a partir da préclassificação das indústrias em tradicional e moderna. O principal resultado é que existe forte relação entre nível de salários e nível tecnológico da indústria, isto é, os trabalhadores mais bem pagos estão nas indústrias modernas e vice-versa para os que estão nas indústrias tradicionais.

Amadeo (1994) examina a determinação de salários no contexto da aceleração inflacionária da década de 1980. A hipótese utilizada é que quanto maiores as rendas de monopólio da indústria, maior o poder de indexação dos salários. Isso porque os empregadores desses setores seriam mais tolerantes à demandas salariais que os empregadores dos setores mais próximos da formação de preços competitivos, sugerindo relação entre mark-up e salários. A proxy de mark-up é preço relativo. Amadeo encontra elevada relação entre preços e salários industriais, o que ele assumiu como evidência do poder de barganha e das características das indústrias para explicar salários.

Barros e Mendonça (1995) investigam a qualidade do emprego no Brasil e, para tanto, examinam os salários por ramo de atividade controlando para fatores como idade, educação, padronização do salário pela jornada de trabalho, mês e ano de 
referência do salário e posse da carteira de trabalho. Os resultados mostram que os salários diferem significativamente por ramo de atividade.

As únicas pesquisas que investigam diferenciais de salários industriais com alguma similaridade metodológica e de propósito deste trabalho são as que seguem. Gatica et alii (1991) examinam a estrutura e diferencial de salários industriais a partir de uma amostra de micro-dados da RAIS de 1987 do setor manufatureiro da cidade de São Paulo. Os resultados indicam forte efeito da indústria na formação dos salários, o que foi atribuído pelos autores aos salários de eficiência.

Pinheiro e Ramos (1994) examinam o diferencial de salários industriais para a classificação a 1 e 2 dígitos utilizando dados das Pesquisa Nacional por Amostras de Domicílio (PNAD) de 1981, 1985 e 1990. Eles encontram que a estrutura de salários é estável ao longo do tempo, alta correlação entre salários de diferentes categorias ocupacionais, e que os modelos estimados explicam cerca de $50 \%$ da dispersão salarial.

Gatica et alii (1995) usam dados individuais da RAIS de 1987 da cidade de São Paulo para investigar os diferenciais de salários inter-industriais a 2 dígitos. Eles também encontram alta correlação entre prêmios salariais de diferentes ocupações da mesma indústria, de trabalhadores com alto e baixo tempo de emprego na firma, de trabalhadores jovens e idosos, e de firmas grandes e pequenas da mesma indústria. Os resultados encontrados sugerem que a filiação industrial seria importante variável para explicar a dispersão salarial.

Mizala e Romaguera (1998) utilizam uma amostra de trabalhadores da RAIS de 1987 do município de São Paulo filiados à 172 firmas do setor manufatureiro para examinar os diferenciais de salários ao nível da firma. Os resultados sugerem que as dummies de firma afetam a determinação dos salários explicando, dessa forma, a dispersão salarial.

\section{Metodologia e Dados}

A metodologia utilizada para estimar os prêmios salariais e seu desvio-padrão segue o modelo proposto por Haisken-DeNew e Schmidt (1997), que corrige e refina o método desenvolvido e popularizado por Krueger and Summers (1988). ${ }^{3}$ As equações de salário são estimadas da seguinte forma:

$$
\ln w_{i j}=\alpha+\beta X_{i}+\varphi Z_{j}+\epsilon_{i j}
$$

onde:

\footnotetext{
${ }^{3}$ Para uma discussão detalhada e comparativa entre os dois métodos, ver Arbache (1999).
} 
$\ln w_{i j}$ é o logaritmo natural do salário real por hora do trabalhador $i$ na indústria $j$;

$X_{i}$ é o vetor de características pessoais, região geográfica, dentre outras variáveis de controle;

$Z_{j}$ é o vetor de dummies de indústria, o qual inclui todas as indústrias; $\alpha$ é o intercepto; $\epsilon_{i j}$ é o distúrbio randômico refletindo as características não observáveis inerentes às estatísticas de salários; e $\beta$ e $\varphi$ são os parâmetros a serem estimados. Como todas as dummies de indústria são incluídas nesse modelo, impõe-se uma restrição linear $\varphi$ da seguinte forma:

$$
\sum_{j} \varphi_{j} n_{j}=0
$$

onde: $n_{j}$ é a participação no emprego da indústria $j$. Os coeficientes reportados são interpretados como a diferença proporcional do salário de um trabalhador da indústria $j$ e o trabalhador médio representativo de todo o conjunto de indústrias em análise. A formulação dada por (1) e (2) fornece, numa única etapa, coeficientes diretamente interpretáveis e com erros-padrão corretos.

O desvio-padrão dos prêmios salariais é calculado da seguinte forma:

$$
S D(\varphi)=\sqrt{n^{\prime}\left(\bar{H}\left(\varphi_{j}\right)\right) \varphi_{j}-n^{\prime} \bar{D}\left(V\left(\varphi_{j}\right)\right)}
$$

onde:

$S D(\varphi)$ provê o desvio-padrão dos coeficientes ajustado e ponderado;

$\bar{H}($.$) transforma o vetor coluna em matriz diagonal cuja diagonal é dada pelo vetor$ coluna;

$\bar{D}$ denota o vetor coluna formado pelos elementos da diagonal da matriz;

$V$ é a matriz de variância e covariância;

$n$ é o vetor de participação no emprego de cada indústria (ver Haisken-DeNew e Schmidt (1997), para mais detalhes).

A análise empírica aqui desenvolvida utiliza micro-dados do Relatório Anual de Informações Sociais de 1996, 1997 e 1998. Contrariamente a todos os demais estudos feitos anteriormente para o Brasil sobre diferenciais de salários industriais, empreende-se, neste artigo, uma investigação muito mais detalhada, pois examinase o diferencial de salários ao nível de 3 dígitos, enquanto que os demais estudos não foram além do nível de desagregação a 2 dígitos. Ademais, e acima de tudo, investigam-se as características dos trabalhadores e da sua firma, e não apenas as características da indústria a que eles estão filiados.

A base de dados utilizada tem informações anuais de mais de 5 milhões de trabalhadores empregados em cerca de 31 mil firmas do setor industrial brasileiro que 
compõem o cadastro amostral das firmas da Pesquisa Industrial Anual. As firmas e os trabalhadores foram identificados pelo CNPJ e pelo PIS, respectivamente.

Para se obter o conjunto de dados empregados na pesquisa, obedeceram-se aos seguintes procedimentos. Na primeira etapa, identificaram-se as firmas e os seus respectivos códigos de atividade econômica através dos CNPJs. Na segunda etapa identificaram-se os trabalhadores vinculados a cada um dos CNPJs utilizando-se os micro-dados da RAIS. Na terceira etapa identificaram-se, para cada CNPJ, as firmas exportadoras e não exportadoras utilizando-se dados da Secretaria de Comércio Exterior. Na quarta etapa identificaram-se, a partir do Censo de Capitais Estrangeiros do Banco Central, os CNPJs referentes às firmas com capital majoritariamente estrangeiro. Dessa forma, reuniu-se o conjunto de informações que possibilitou atender aos objetivos da pesquisa. Destaque-se que o fator de ligação entre os diferentes bancos de dados são os CNPJs das firmas. ${ }^{4}$

A partir dos micro-dados da RAIS foram obtidas as características da mão-deobra como idade, gênero e tempo de emprego do trabalhador na firma, além do salário. As demais variáveis investigadas foram construídas. A variável de pessoal ocupado na firma foi construída como pessoal ocupado médio durante o ano, calculada da seguinte forma: somatório do número de trabalhadores empregados mensalmente na firma dividido por doze.

O procedimento metodológico para obtenção da variável escolaridade é como segue. Na RAIS, a informação sobre a qualificação educacional do trabalhador é uma variável discreta e informa o estágio do ensino regular concluso ou inconcluso do indivíduo. A partir das categorias educacionais apresentadas na RAIS, buscouse a informação sobre tempo de estudo na PNAD. O procedimento utilizado foi selecionar, nos micro-dados da PNAD, os trabalhadores do setor industrial com carteira assinada no trabalho principal. Utilizaram-se apenas os trabalhadores com carteira assinada, pois a RAIS cobre somente os trabalhadores com contrato formal de trabalho. Nesse subconjunto de trabalhadores buscou-se a informação sobre o tempo de estudo médio em cada categoria educacional semelhante à categoria educacional apresentada pela RAIS. Dessa forma, foi possível imputar o tempo de estudo do trabalhador e tornar contínua a variável que informa a qualificação educacional do trabalhador na RAIS. Com o tempo de estudo sendo uma variável contínua tornou-se mais fácil o tratamento estatístico da série e tornou-se possível a construção da variável experiência. A variável experiência foi construída na forma padrão: idade menos o tempo de estudo menos seis.

${ }^{4}$ Acreditamos que não haja maiores problemas em compatibilizar dados de diferentes bancos, posto que o CNPJ, fator de ligação entre eles, é rigorosamente controlado pela Secretaria da Receita Federal. 
Na PIA, todas as firmas com trinta ou mais empregados fazem parte da amostra pesquisada, enquanto que, para a população de firmas com menos de trinta empregados, é feita uma amostragem aleatória. Conseqüentemente, as grandes empresas têm maior peso relativo na amostra analisada do que as empresas médias e pequenas. O quadro abaixo apresenta um resumo das principais variáveis empregadas no estudo:

\begin{tabular}{lccc}
\hline $\begin{array}{l}\text { Variável e número de } \\
\text { observações por ano }\end{array}$ & 1996 & 1997 & 1998 \\
\hline Trabalhadores & 5.745 .285 & 5.546 .228 & 5.090 .239 \\
Firmas & 29.821 & 29.320 & 31.030 \\
Indústrias & 99 & 99 & 99 \\
\hline
\end{tabular}

\section{Resultados}

\section{Filiação industrial e dispersão salarial ${ }^{5}$}

Os resultados dos prêmios salariais para o ano de 1998 estão reportados na tabela $1 .^{6}$ Os coeficientes na coluna 1 mostram a diferença proporcional entre o salário de um trabalhador na indústria $i$ e o salário ponderado médio de um trabalhador representativo de todas as indústrias. O coeficiente na primeira linha, por exemplo, mostra que um trabalhador representativo da indústria de extração de carvão mineral ganhava, em média, 52,8\% a mais que o trabalhador representativo de todo o conjunto de indústrias, enquanto um trabalhador da indústria de extração de pedra, areia e argila ganhava $20,5 \%$ a menos. ${ }^{7}$ O desvio-padrão ponderado e ajustado dos prêmios salariais é de $46,8 \%$ (ver ante-penúltima linha da tabela), sugerindo que a dispersão dos salários é bastante elevada. Assim, a filiação industrial parece exercer importante efeito na determinação dos salários no Brasil.

O resultado da tabela pode, no entanto, estar superestimado, já que os trabalhadores podem ter diferentes características produtivas, bem como as firmas a que estão filiados podem ter características que contribuam para a formação dos salários. Nesse caso, é necessário corrigir o modelo para os atributos dos indivíduos

\footnotetext{
${ }^{5}$ Para um exame dos diferenciais de salários industriais de toda a economia, ver Arbache (2003).

${ }^{6}$ Os resultados referentes aos anos 1996 e 1997 estão disponíveis e podem ser enviados mediante solicitação aos autores. Os resultados qualitativos e quantitativos desses anos são bastante similares aos de 1998.

${ }^{7}$ Calculado como: $\left(e^{\beta_{i}}-1\right) * 100$.
} 
e firmas. Os resultados controlados encontram-se nas colunas 2 e 3 . Os controles utilizados para calcular os resultados da coluna 2 foram: anos de educação, tempo de emprego na firma, experiência e experiência ao quadrado, gênero, região geográfica, 8 dummies de categoria ocupacional (CBO a 1 dígito) e 7 dummies de tamanho da firma. Na coluna 3 utilizaram-se esses mesmos controles e ainda dummies que identificam se a firma é exportadora, se é multinacional e uma interação entre ambas.

Uma vez empregados os controles, observa-se que o prêmio da indústria de extração de pedra, areia e argila, por exemplo, passou de negativo a positivo, indicando que, na verdade, mantidas constantes as características dos trabalhadores e firmas, paga-se, em média, mais nessa indústria que a média paga pelas indústrias examinadas. Ou seja, o sinal negativo da coluna 1 indica, por exemplo, que os trabalhadores da indústria de extração de pedra, areia e argila são, em média, menos qualificados, levando-os a ganhar menos. Mas, uma vez controladas as características individuais e da firma, eles passam a ganhar relativamente mais que a média geral.

A tabela A1, em anexo, mostra os coeficientes estimados das covariadas do modelo 3. Um ano a mais de escolaridade implica em aumento de 9,5\% do salário. Um ano adicional de experiência promove um aumento de $5 \%$ do salário, enquanto que um mês a mais de emprego na firma contribui para elevar o salário em $0,2 \%$. Homens com mesmas características e ocupação das mulheres percebem um prêmio salarial de $33 \%$. Os coeficientes de tamanho da firma mostram crescimento monotônico. Enquanto uma firma com 11 a 50 trabalhadores paga um prêmio de $7,3 \%$ com relação às firmas com 1 a 10 trabalhadores, que é a categoria base, as firmas com mais de 1000 trabalhadores pagam 50\% de prêmio. Logo, parece haver forte relação entre tamanho, tecnologia e prêmio, tal como propõem os modelos de salários de eficiência e a literatura empírica (Hamermesh, 1980, Dickens e Katz, 1987, Mellow, 1982, Brown e Medoff, 1989).

As firmas exportadoras pagam 13,6\% de prêmio, o que está de acordo com Arbache e De Negri (2003), e sugere que estas têm maior produtividade e/ou gozam de algum grau de renda de monopólio. As multinacionais pagam prêmio salarial de $38,3 \%$, sugerindo que estas também gozam de algum grau de renda de monopólio, o que pode estar associado às características dos mercados em que elas operam e da tecnologia que empregam.

A dispersão dos prêmios salariais caiu de $46,8 \%$ para $20 \%$ no modelo 2 , e para $19 \%$ no modelo 3 . Esse resultado sugere que os controles utilizados têm grande poder explicativo reduzindo, conseqüentemente, a importância da filiação industrial nos salários. O coeficiente de determinação sobe de $28 \%$, no modelo 1 , 
para $62 \%$, no modelo 3 , sugerindo que cerca de $2 / 3$ da variância dos salários pode ser explicada pelas características dos indivíduos e das firmas. Entretanto, cerca de $38 \%$ da dispersão permanece, ainda, sem explicação, o que pode estar associado à fatores como características da firma e indústria e habilidades não mensuradas. Os coeficientes de correlação de Pearson entre o vetor de prêmios controlados e não controlados são de 0,92 e 0,88 para os modelos 2 e 3, respectivamente, sugerindo que, embora os controles exerçam enorme efeito sobre o tamanho dos prêmios, eles não são capazes de mudar a estrutura de salários. ${ }^{8}$

Tabela 1

Prêmio salarial industrial - 1998

\begin{tabular}{|c|c|c|c|c|}
\hline CNAE & Indústria & $\begin{array}{c}\text { Modelo } 1- \\
\text { sem } \\
\text { controle }\end{array}$ & $\begin{array}{c}\text { Modelo } 2- \\
\text { com } \\
\text { controle }\end{array}$ & $\begin{array}{c}\text { Modelo } 3- \\
\text { com } \\
\text { controle }\end{array}$ \\
\hline 100 & $\begin{array}{l}\text { Extração de carvão mineral } \\
\text { Serviços relacionados com a extração de petróleo e gás }\end{array}$ & 0,4240 & 0,3061 & 0,4044 \\
\hline 112 & - exceto a prospecção realizada por terceiros & 0,3494 & 0,4355 & 0,5201 \\
\hline 131 & Extração de minério de ferro & 0,9594 & 0,2708 & 0,3168 \\
\hline 132 & Extração de minerais metálicos não-ferrosos & 0,3321 & 0,3420 & 0,3447 \\
\hline 141 & Extração de pedra, areia e argila & $-0,1870$ & 0,0522 & 0,0802 \\
\hline 142 & Extração de outros minerais não-metálicos & $-0,2705$ & $-0,1182$ & $-0,1088$ \\
\hline 151 & $\begin{array}{l}\text { Abate e preparação de produtos de carne e de pescado } \\
\text { Processamento, preservação e produção de conservas de }\end{array}$ & $-0,2881$ & $-0,1479$ & $-0,1232$ \\
\hline 152 & frutas, legumes e outros vegetais & $-0,5279$ & $-0,2045$ & $-0,2100$ \\
\hline 153 & Produção de óleos e gorduras vegetais e animais & 0,0222 & $-0,0636$ & $-0,0768$ \\
\hline 154 & Laticínios & 0,1139 & $-0,0758$ & $-0,0843$ \\
\hline 155 & $\begin{array}{l}\text { Moagem, fabricação de produtos amiláceos e de rações } \\
\text { balanceadas para animais }\end{array}$ & $-0,0004$ & $-0,0246$ & 0,0118 \\
\hline 156 & Fabricação e refino de açúcar & $-0,5434$ & $-0,0685$ & $-0,0344$ \\
\hline 157 & Torrefação e moagem de café & $-0,1740$ & $-0,1942$ & $-0,1646$ \\
\hline 158 & Fabricação de outros produtos alimentícios & $-0,2423$ & $-0,1476$ & $-0,1226$ \\
\hline 159 & Fabricação de bebidas & 0,2276 & 0,0636 & 0,1178 \\
\hline 160 & Fabricação de produtos do fumo & $-0,3116$ & $-0,2035$ & $-0,3422$ \\
\hline 172 & Fiação & $-0,3360$ & $-0,1896$ & $-0,2143$ \\
\hline 173 & Tecelagem - inclusive fiação e tecelagem & $-0,2766$ & $-0,2610$ & $-0,2420$ \\
\hline 174 & Fabricação de artefatos têxteis, incluindo tecelagem & $-0,2689$ & $-0,1417$ & $-0,1295$ \\
\hline 175 & Serviços de acabamento em fios, tecidos e artigos têxteis & $-0,1596$ & 0,0776 & 0,1171 \\
\hline 176 & $\begin{array}{l}\text { Fabricação de artefatos têxteis a partir de tecidos - } \\
\text { exclusive vestuário - e de outros artigos têxteis }\end{array}$ & $-0,1686$ & $-0,0364$ & $-0,0425$ \\
\hline 177 & Fabricação de tecidos e artigos de malha & $-0,2924$ & $-0,1038$ & $-0,0685$ \\
\hline 181 & Confecção de artigos do vestuário & $-0,5617$ & $-0,1973$ & $-0,1669$ \\
\hline 182 & $\begin{array}{l}\text { Fabricação de acessórios do vestuário e de segurança } \\
\text { profissional }\end{array}$ & $-0,4095$ & $-0,1079$ & $-0,1217$ \\
\hline 191 & Curtimento e outras preparações de couro & $-0,3720$ & $-0,1069$ & $-0,1416$ \\
\hline 192 & $\begin{array}{l}\text { Fabricação de artigos para viagem e de } \\
\text { artefatos diversos de couro }\end{array}$ & $-0,5425$ & $-0,2338$ & $-0,2355$ \\
\hline 193 & Fabricação de calcados & $-0,6167$ & $-0,3468$ & $-0,3395$ \\
\hline 201 & Desdobramento de madeira & $-0,7837$ & $-0,2652$ & $-0,2833$ \\
\hline 202 & $\begin{array}{l}\text { Fabricação de produtos de madeira, cortiça e } \\
\text { material trancado - exclusive móveis }\end{array}$ & $-0,5325$ & $-0,2341$ & $-0,2434$ \\
\hline 211 & $\begin{array}{l}\text { Fabricação de celulose e outras pastas } \\
\text { para a fabricação de papel }\end{array}$ & 0,7933 & 0,4262 & 0,4500 \\
\hline 212 & Fabricação de papel, papelão liso, cartolina e cartão & 0,4036 & 0,1544 & 0,1645 \\
\hline 213 & Fabricação de embalagens de papel ou papelão & 0,0975 & 0,0636 & 0,0680 \\
\hline
\end{tabular}

${ }^{8}$ Os vetores de diferenciais de salários aqui encontrados não são diretamente comparáveis aos dos demais estudos para o Brasil devido à diferença de desagregação industrial. 


\begin{tabular}{|c|c|c|c|c|}
\hline 214 & $\begin{array}{l}\text { Fabricação de artefatos diversos de papel, papelão, } \\
\text { cartolina e cartão }\end{array}$ & 0,1456 & 0,0730 & 0,0510 \\
\hline 221 & Edição, edição e impressão & 0,4322 & 0,1295 & 0,1993 \\
\hline 222 & Impressão e serviços conexos para terceiros & 0,1809 & 0,1899 & 0,2229 \\
\hline 223 & Reprodução de materiais gravados & 0,3254 & 0,1677 & 0,1658 \\
\hline 232 & Refino de petróleo & 1,7168 & 0,7987 & 0,8437 \\
\hline 234 & Produção de álcool & $-0,4342$ & $-0,0743$ & $-0,0028$ \\
\hline 241 & Fabricação de produtos químicos inorgânicos & 0,4420 & 0,1178 & 0,1264 \\
\hline 242 & Fabricação de produtos químicos orgânicos & 0,7387 & 0,4172 & 0,3790 \\
\hline 243 & Fabricação de resinas e elastômeros & 1,1380 & 0,6120 & 0,5275 \\
\hline 244 & $\begin{array}{l}\text { Fabricação de fibras, fios, cabos e filamentos } \\
\text { contínuos artificiais e sintéticos }\end{array}$ & 0,4687 & 0,0961 & 0,1297 \\
\hline 245 & Fabricação de produtos farmacêuticos & 0,6202 & 0,2588 & 0,2042 \\
\hline 246 & Fabricação de defensivos agrícolas & 1,0985 & 0,5168 & 0,4092 \\
\hline 247 & $\begin{array}{l}\text { Fabricação de sabões, detergentes, produtos de limpeza } \\
\text { e artigos de perfumaria }\end{array}$ & 0,1890 & 0,0491 & 0,0280 \\
\hline 248 & $\begin{array}{l}\text { Fabricação de tintas, vernizes, esmaltes, } \\
\text { lacas e produtos afins }\end{array}$ & 0,5637 & 0,3072 & 0,2530 \\
\hline 249 & Fabricação de produtos e preparos químicos diversos & 0,3292 & 0,1578 & 0,0811 \\
\hline 251 & Fabricação de artigos de borracha & 0,3117 & 0,1506 & 0,1009 \\
\hline 252 & Fabricação de produtos de plástico & $-0,0012$ & 0,0452 & 0,0494 \\
\hline 261 & Fabricação de vidro e de produtos do vidro & 0,3482 & 0,1310 & 0,0522 \\
\hline 262 & Fabricação de cimento & 0,5842 & 0,2439 & 0,3008 \\
\hline 263 & $\begin{array}{l}\text { Fabricação de artefatos de concreto, } \\
\text { cimento, fibrocimento, gesso e estuque }\end{array}$ & $-0,1821$ & $-0,0415$ & 0,0165 \\
\hline 264 & Fabricação de produtos cerâmicos & $-0,4538$ & $-0,2034$ & $-0,1858$ \\
\hline 269 & $\begin{array}{l}\text { Aparelhamento de pedras e fabricação de cal e de } \\
\text { outros produtos de minerais não-metálicos }\end{array}$ & $-0,2403$ & $-0,0576$ & $-0,0773$ \\
\hline 271 & Siderúrgicas Integradas & 0,9824 & 0,2215 & 0,2529 \\
\hline 272 & $\begin{array}{l}\text { Fabricação de produtos siderúrgicos - } \\
\text { exclusive em siderúrgicas integradas }\end{array}$ & 0,1581 & 0,1178 & 0,0959 \\
\hline 273 & $\begin{array}{l}\text { Fabricação de tubos - } \\
\text { exclusive em siderúrgicas integradas }\end{array}$ & 0,2662 & 0,1158 & 0,1146 \\
\hline 274 & Metalurgia de metais não-ferrosos & 0,5605 & 0,2416 & 0,2155 \\
\hline 275 & Fundição & $-0,0029$ & $-0,0026$ & $-0,0029$ \\
\hline 281 & $\begin{array}{l}\text { Fabricação de estruturas metálicas e } \\
\text { obras de caldeiraria pesada }\end{array}$ & 0,0173 & 0,0414 & 0,0842 \\
\hline 282 & Fabricação de tanques, caldeiras e reservatórios metálicos & 0,1909 & 0,1435 & 0,1499 \\
\hline 283 & $\begin{array}{l}\text { Forjaria, estamparia, metalurgia do pó e } \\
\text { serviços de tratamento de metais }\end{array}$ & 0,1078 & 0,1617 & 0,1825 \\
\hline 284 & $\begin{array}{l}\text { Fabricação de artigos de cutelaria, de serralheria e } \\
\text { ferramentas manuais }\end{array}$ & 0,1149 & 0,0502 & 0,0393 \\
\hline 289 & Fabricação de produtos diversos de metal & 0,1161 & 0,1198 & 0,1219 \\
\hline 291 & $\begin{array}{l}\text { Fabricação de motores, bombas, compressores e } \\
\text { equipamentos de transmissão }\end{array}$ & 0,4476 & 0,1770 & 0,1064 \\
\hline 292 & Fabricação de maquinas e equipamentos de uso geral & 0,3542 & 0,1931 & 0,1642 \\
\hline 293 & $\begin{array}{l}\text { Fabricação de tratores e de maquinas e equipamentos para } \\
\text { a agricultura, avicultura e obtenção de produtos animais }\end{array}$ & 0,1406 & $-0,0039$ & $-0,0221$ \\
\hline 294 & Fabricação de máquinas-ferramenta & 0,5230 & 0,3243 & 0,2565 \\
\hline 295 & $\begin{array}{l}\text { Fabricação de maquinas e equipamentos para } \\
\text { as industrias de extração mineral e construção }\end{array}$ & 0,5141 & 0,1974 & 0,1073 \\
\hline 296 & $\begin{array}{l}\text { Fabricação de outras maquinas e equipamentos } \\
\text { de uso específico }\end{array}$ & 0,3780 & 0,2410 & 0,2239 \\
\hline 297 & Fabricação de armas, munições e equipamentos militares & 0,1660 & $-0,2408$ & $-0,2205$ \\
\hline 298 & Fabricação de eletrodomésticos & 0,2513 & 0,0280 & 0,0240 \\
\hline 302 & $\begin{array}{l}\text { Fabricação de maquinas e equipamentos de sistemas } \\
\text { eletrônicos para processamento de dados }\end{array}$ & 0,4254 & 0,2197 & 0,2427 \\
\hline 311 & Fabricação de geradores, transformadores e motores elétricos & 0,4075 & 0,1391 & 0,0964 \\
\hline
\end{tabular}




\begin{tabular}{|c|c|c|c|c|}
\hline 312 & $\begin{array}{l}\text { Fabricação de equipamentos para distribuição e } \\
\text { controle de energia elétrica }\end{array}$ & 0,1693 & 0,0679 & 0,0333 \\
\hline 313 & Fabricação de fios, cabos e condutores elétricos isolados & 0,2657 & 0,1223 & 0,1170 \\
\hline 314 & Fabricação de pilhas, baterias e acumuladores elétricos & 0,4314 & 0,2231 & 0,1426 \\
\hline 315 & Fabricação de lâmpadas e equipamentos de iluminação & 0,0576 & 0,0145 & $-0,0541$ \\
\hline 316 & $\begin{array}{l}\text { Fabricação de material elétrico para veículos - } \\
\text { exclusive baterias }\end{array}$ & 0,4921 & 0,1682 & 0,0685 \\
\hline 319 & Fabricação de outros equipamentos e aparelhos elétricos & 0,1309 & 0,1626 & 0,1409 \\
\hline 321 & Fabricação de material eletrônico básico & 0,5118 & 0,2580 & 0,1866 \\
\hline 322 & $\begin{array}{l}\text { Fabricação de aparelhos e equipamentos de telefonia e } \\
\text { radiotelefonia e de transmissores de televisão e radio }\end{array}$ & 0,8217 & 0,3734 & 0,3974 \\
\hline 323 & $\begin{array}{l}\text { Fabricação de aparelhos receptores de radio e televisão } \\
\text { e de reprodução, gravação ou amplificação de som e vídeo }\end{array}$ & 0,1940 & 0,0184 & 0,0251 \\
\hline 331 & $\begin{array}{l}\text { Fabricação de aparelhos e instrumentos para usos } \\
\text { médico-hospitalares, odontológicos e de laboratórios e } \\
\text { aparelhos ortopédicos }\end{array}$ & 0,1057 & 0,0006 & $-0,0710$ \\
\hline 332 & $\begin{array}{l}\text { Fabricação de aparelhos e instrumentos de medida, } \\
0,1911 \\
\text { teste e controle - exclusive equipamentos para controle } \\
\text { de processos industriais }\end{array}$ & 0,0647 & $-0,0128$ & \\
\hline 334 & $\begin{array}{l}\text { Fabricação de aparelhos, instrumentos e materiais ópticos, } \\
\text { fotográficos e cinematográficos }\end{array}$ & 0,0816 & 0,0731 & 0,0258 \\
\hline 335 & Fabricação de cronômetros e relógios & 0,0882 & 0,0642 & 0,0703 \\
\hline 341 & Fabricação de automóveis, caminhonetas e utilitários & 1,0786 & 0,4399 & 0,2860 \\
\hline 342 & Fabricação de caminhões e ônibus & 1,1979 & 0,4576 & 0,3310 \\
\hline 343 & Fabricação de cabines, carrocerias e reboques & 0,2113 & 0,0847 & 0,1058 \\
\hline 344 & Fabricação de pecas e acessórios para veículos automotores & 0,4459 & 0,1759 & 0,1390 \\
\hline 345 & $\begin{array}{l}\text { Recondicionamento ou recuperação de motores para veículos } \\
\text { automotores }\end{array}$ & $-0,2495$ & $-0,1180$ & $-0,0742$ \\
\hline 351 & Construção e reparação de embarcações & 0,0797 & 0,1155 & 0,1370 \\
\hline 352 & Construção, montagem e reparação de veículos ferroviários & 0,4989 & 0,1197 & 0,1449 \\
\hline 353 & Construção, montagem e reparação de aeronaves & 0,9510 & 0,2829 & 0,3197 \\
\hline 359 & Fabricação de outros equipamentos de transporte & 0,2392 & 0,1721 & 0,1709 \\
\hline 361 & Fabricação de artigos do mobiliário & $-0,3632$ & $-0,1667$ & $-0,1549$ \\
\hline 369 & Fabricação de produtos diversos & $-0,2193$ & $-0,1180$ & $-0,1385$ \\
\hline 372 & Reciclagem de sucatas não-metálicas & $-0,0512$ & $-0,0091$ & $-0,0819$ \\
\hline Desvio & padrão ajustado e ponderado & 0,4680 & 0,2002 & 0,1888 \\
\hline $\mathrm{R}^{2}$ ajustado & & 0,2777 & 0,6146 & 0,6221 \\
\hline Teste F & & 1372 & 4610 & 4643 \\
\hline
\end{tabular}

\section{Características das Indústrias que Pagam Altos e Baixos Prêmios Salariais}

Embora as evidências acima tenham mostrado que as características individuais e da firma contribuem para explicar a dispersão salarial, elas sugerem que há, ainda, uma parcela significativa da dispersão a ser explicada, e que esta pode estar associada às características das indústrias. Se esse é o caso, teríamos que identificar características comuns entre as indústrias que pagam os maiores e os menores prêmios salariais. Com o objetivo de investigar o possível efeito de características industriais sobre a formação do prêmio salarial, a tabela 2 lista as 15 indústrias com os maiores prêmios e as 15 indústrias com os menores prêmios salariais.

A tabela mostra que as indústrias que pagam os maiores prêmios salariais são aquelas que normalmente empregam tecnologias de produção mais avançadas como, por exemplo, as indústrias química, eletro-eletrônica, aviação, veículos e 
bens de capital, bem como são indústrias concentradas como, por exemplo, a indústria de refino e extração de petróleo e fabricação de cimento. Do outro lado estão as indústrias com características opostas como, por exemplo, as indústrias de alimentos, vestuário, têxteis, calçados, móveis e mobiliários, que têm baixo nível tecnológico e encontram-se em mercados mais competitivos. Logo, parece haver relação direta entre prêmios salariais, tecnologia e grau de concentração industrial.

Tabela 2

Prêmios salariais industriais mais elevados e mais baixos - 1998

\begin{tabular}{|c|c|c|c|}
\hline Indústrias com prêmios mais elevados & Prêmio & Indústrias com prêmios mais baixos & Prêmio \\
\hline Refino de petróleo & 0,8437 & Fabricação de produtos diversos & $-0,1385$ \\
\hline Fabricação de resinas e elastômeros & 0,5275 & $\begin{array}{l}\text { Curtimento e outras preparações } \\
\text { de couro }\end{array}$ & $-0,1416$ \\
\hline \multicolumn{4}{|l|}{$\begin{array}{l}\text { Serviços relacionados com a extração de } \\
\text { petróleo e gás - exceto a prospecção }\end{array}$} \\
\hline realizada por terceiros & 0,5201 & Fabricação de artigos do mobiliário & $-0,1549$ \\
\hline $\begin{array}{l}\text { Fabricação de celulose e outras pastas } \\
\text { para a fabricação de papel }\end{array}$ & 0,4500 & Torrefação e moagem de café & $-0,1646$ \\
\hline Fabricação de defensivos agrícolas & 0,4092 & Confecção de artigos do vestuário & $-0,1669$ \\
\hline Extração de carvão mineral & 0,4044 & Fabricação de produtos cerâmicos & $-0,1858$ \\
\hline \multicolumn{3}{|l|}{$\begin{array}{l}\text { Fabricação de aparelhos e equipamentos } \\
\text { de telefonia e radiotelefonia }\end{array}$} & \\
\hline & & frutas, legumes e outros vegetais & $-0,2100$ \\
\hline Fabricação de produtos químicos orgânicos & 0,3790 & Fiação & $-0,2143$ \\
\hline Extração de minerais metálicos não-ferrosos & 0,3447 & $\begin{array}{l}\text { Fabricação de armas, munições e } \\
\text { equipamentos militares }\end{array}$ & $-0,2205$ \\
\hline Fabricação de caminhões e ônibus & 0,3310 & $\begin{array}{l}\text { Fabricação de artigos para viagem e } \\
\text { de artefatos diversos de couro }\end{array}$ & $-0,2355$ \\
\hline $\begin{array}{l}\text { Construção, montagem e reparação } \\
\text { de aeronaves }\end{array}$ & 0,3197 & $\begin{array}{l}\text { Tecelagem - inclusive fiação e } \\
\text { tecelagem }\end{array}$ & $-0,2420$ \\
\hline Extração de minério de ferro & 0,3168 & $\begin{array}{l}\text { Fabricação de produtos de madeira, } \\
\text { cortiça e material trancado } \\
\text { - exclusive moveis }\end{array}$ & $-0,2434$ \\
\hline Fabricação de cimento & 0,3008 & Desdobramento de madeira & $-0,2833$ \\
\hline $\begin{array}{l}\text { Fabricação de automóveis, caminhonetas } \\
\text { e utilitários }\end{array}$ & 0,2860 & Fabricação de calçados & $-0,3395$ \\
\hline Fabricação de máquinas-ferramenta & 0,2565 & Fabricação de produtos do fumo & $-0,3422$ \\
\hline
\end{tabular}

A figura 1 mostra a relação entre prêmio salarial industrial e educação média das firmas por indústria. Ou seja, calculou-se a escolaridade média dos trabalhadores de cada firma da indústria $i$ e em seguida calculou-se a média da escolaridade das firmas da indústria. Desta forma, temos a média da média. A figura sugere que as indústrias com maiores prêmios salariais são aquelas cujas firmas têm os maiores níveis médios de escolaridade, confirmando haver associação entre nível tecnológico e prêmio salarial, ou seja, as indústrias mais sofisticadas ou que 
utilizam força de trabalho mais qualificada teriam maior produtividade justificando, ao menos parcialmente, o maior prêmio salarial. ${ }^{9}$

Figura 1

Prêmio salarial industrial e escolaridade média na firma

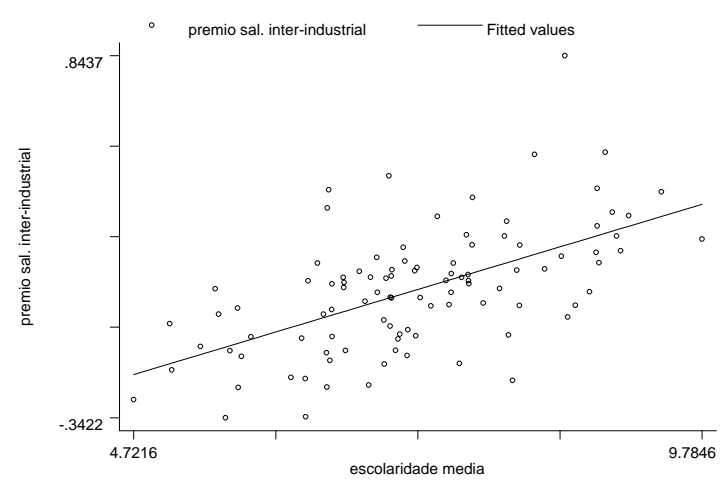

Figura 2

Prêmio salarial industrial e tempo médio de trabalho na firma

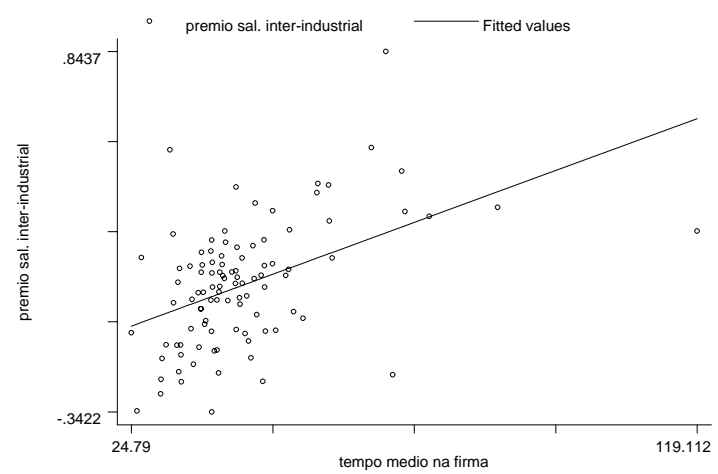

Nessa mesma linha, a figura 2 mostra a relação entre prêmio salarial industrial e tempo médio de trabalho nas firmas por indústria. A figura sugere que as indústrias cujas firmas têm tempo médio de contrato de trabalho mais longo e estável são também aquelas cujos prêmios são mais elevados, o que afetaria a pro-

\footnotetext{
${ }^{9}$ Os prêmios salariais utilizados nas figuras e exercícios a seguir referem-se aos prêmios do modelo 3 da tabela 1 .
} 
dutividade e o desempenho dos trabalhadores através de fatores como learningby-doing, por exemplo.

Figura 3

Prêmio salarial industrial e valor adicionado por trabalhador na firma

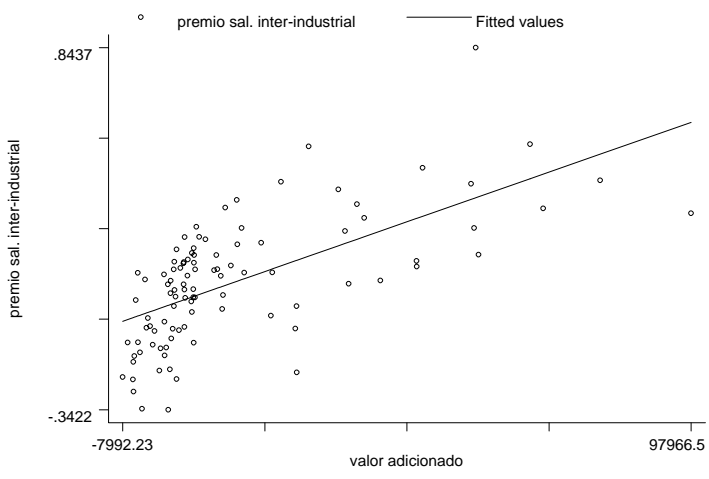

A figura 3 mostra a relação entre valor adicionado médio por trabalhador das firmas por indústria e prêmio salarial industrial. A figura indica que as indústrias cujas firmas têm maiores níveis médios de valor adicionado são as que pagam maiores prêmios salariais. O maior valor adicionado por trabalhador pode resultar de fatores como habilidades não mensuradas e tecnologia mais sofisticada da firma. Resta saber se a eventual maior concentração de trabalhadores com habilidades não mensuradas nas firmas e indústrias tecnologicamente mais avançadas é coincidência ou resultado de matching endógeno, tal como sugere o modelo de Gibbons e Katz (1992).

A tabela 2 e as figuras 1 a 3 sugerem haver diferenças entre as características tecnológicas e de mercado das indústrias que pagam altos e baixos prêmios salariais. Sendo assim, essas características teriam potencial contribuição explicativa para os diferenciais de salários industriais. Com o objetivo de investigar os determinantes dos prêmios salariais industriais empregamos a metodologia proposta por Sarquis e Arbache (2001). Considere a diferença de salários entre um trabalhador representativo da indústria $j$ e o salário de um trabalhador representativo de todo o conjunto de indústrias:

$$
\varphi_{j t}=\mu_{j t}-\mu_{t}
$$

O prêmio da indústria $j$ no tempo $t$ é determinado pelas características da indústria no tempo $t$. Assume-se que deve haver alguma correlação do termo 
erro não apenas com características específicas das indústrias, como é usual, mas, também, com o tempo, devido às mudanças por que passou a economia no período em análise:

$$
\begin{gathered}
\mu_{j t}=\theta+\phi Y_{j t}+\gamma E_{j t}+u_{j t} \\
u_{j t}=e_{j t}+v_{j}+\delta_{t}
\end{gathered}
$$

onde:

$Y$ é o vetor de características industriais variando ao longo do tempo, e $E$ é o vetor de características individuais medidos em valores médios para a indústria $j$ no período $t$. O termo erro reflete os efeitos randômicos não observados inerentes aos componentes da indústria e período, que devem ser correlacionados com as variáveis explicativas do painel.

De acordo com a nossa definição de diferencial de salários, que se deve às especificidades da indústria ao longo do tempo, a diferença entre o salário e o salário médio das indústrias é:

$$
\varphi_{j t}=\phi\left(Y_{j t}-Y_{t}\right)+\gamma\left(E_{j t}-E_{t}\right)+\left(u_{j t}-u_{t}\right)
$$

onde

$$
u_{j t}-u_{t}=e_{j t}-e_{t}+v_{j}-\bar{v}_{j}
$$

Nesse painel, os efeitos fixos são uma decorrência imediata devido à eliminação do termo correlacionado em $t$ presente em (6). Caso consideremos os efeitos do tempo no erro mais importantes que os efeitos fixos ou efeitos específicos das indústrias, os efeitos randômicos teriam, então, maior relevância no modelo.

Os resultados de três diferentes especificações do modelo (7) encontram-se na tabela 3. O modelo 1 apresenta evidências de que existem externalidades da educação, tempo médio de emprego, margem de lucro e participação de homens na força de trabalho das firmas nos salários. Assim, indústrias com maiores níveis médios de escolaridade teriam maiores prêmios salariais, e vice-versa para as indústrias com menores níveis de escolaridade. O mesmo ocorre com tempo médio de emprego, medido em meses. Esse resultado sugere que o capital humano eleva a produtividade não apenas individual, mas, também, coletiva, o que ocorreria através das externalidades do capital humano, tal como proposto por Lucas (1988). O efeito da margem de lucro pode resultar da demanda dos trabalhadores 
por participação nos resultados das firmas. ${ }^{10}$ A identificação do efeito da participação dos homens na explicação do prêmio pode resultar de fatores como maior compromisso destes com a carreira, que os levaria a se dedicarem mais ao trabalho, e discriminação contra mulheres. As especificações 2 e 3 encontram apenas um pequeno efeito da participação dos homens na força de trabalho nos prêmios. No modelo 3, margem de lucro deixa de ser estatisticamente significante, indicando pouca robustez do coeficiente.

É importante notar que o coeficiente da variável tamanho médio das firmas das indústrias mostrou-se bastante pequeno ou não significativo nos três modelos, sugerindo que os efeitos de tamanho sobre o desempenho aconteceriam apenas ao nível da firma, e não da indústria, como mostram Arbache e De Negri (2003). Assim, o tamanho da firma, que seria proxy de tecnologia e monitoramento, estaria afetando apenas os trabalhadores da própria planta industrial. Dessa forma, duas firmas de uma mesma indústria poderiam ser diferentemente afetadas por tecnologia. Os coeficientes de margem de lucro e valor adicionado são positivos, mas pequenos, pouco robustos ou estatisticamente não significativos, indicando que eventuais efeitos de rent-sharing estariam restritos à firma e não à indústria.

Tabela 3

Efeitos das características das indústrias no prêmio salarial

\begin{tabular}{|c|c|c|c|c|c|c|}
\hline \multicolumn{7}{|c|}{ Variável dependente - prêmio salarial industrial } \\
\hline & Mod & o 1 & Moc & o 2 & Mod & o 3 \\
\hline Variável independente & Coef. & $\mathrm{z}$ & Coef. & $\mathrm{z}$ & Coef. & $\mathrm{z}$ \\
\hline Educação média na indústria & 0,081 & 6,71 & & & & \\
\hline Tempo de emprego médio na indústria & 0,003 & 2,64 & & & & \\
\hline Tamanho médio das firmas na indústria & 0,000 & 0,2 & 0,000 & 1,1 & 0,000 & 1,94 \\
\hline Valor adicionado médio na indústria & & & 0,000 & 6,13 & & \\
\hline Margem de lucro médio das firmas da ind. & 0,049 & 1,84 & & & 0,451 & 1,67 \\
\hline Participação de homens nas firmas da ind. & 0,055 & 5,89 & 0,004 & 4,63 & 0,005 & 4,55 \\
\hline $\mathrm{R}^{2}$ ajustado & 0,52 & & 0,41 & & 0,20 & \\
\hline Teste de Wald & 120,9 & & 77,6 & & 30,2 & \\
\hline Número de observações & 297 & & 297 & & 297 & \\
\hline Número de grupos & 99 & & 99 & & 99 & \\
\hline
\end{tabular}

\section{Regularidade da Estrutura de Salários}

Apesar da relevância das covariadas para explicar os prêmios salariais, as evidências acima sugerem que a filiação industrial tem importante impacto na determinação de salários. Algumas indústrias parecem pagar sempre mais para os seus trabalhadores, enquanto outras indústrias pagam sempre menos para a sua força de trabalho, o que sugere que elas têm distintas avaliações dos atributos dos

\footnotetext{
${ }^{10}$ Resultado similar foi encontrado por Menezes-Filho e Arbache (2003).
} 
trabalhadores e/ou que a produtividade marginal dos trabalhadores com características semelhantes varia entre as indústrias. A estrutura de salários iria ser estável no período analisado se: elementos de rigidez, como salários de eficiência e rent-sharing, dominassem a determinação de salários; os efeitos da redução das barreiras comerciais fosse similar entre as indústrias, ou que os efeitos da abertura fossem similares entre elas; os efeitos da privatização e desregulamentação de mercados fossem igualmente similares entre as indústrias; e os efeitos de outros fatores, como mudanças institucionais e tecnologia, afetassem as indústrias na mesma forma e direção. Nesses casos, haveria pouca realocação de recursos e mudanças na estrutura tecnológica.

Com o objetivo de examinar a estrutura de salários, calculou-se o coeficiente de correlação entre os prêmios salariais ao longo do tempo. Os resultados na tabela 4 mostram que a estrutura de salários é bastante estável, mesmo ao nível de desagregação a 3 dígitos. Poder-se-ia esperar que num ambiente de mudanças, como foi a segunda metade da década de 1990, houvesse realocações inter-setoriais de fatores de produção afetando, assim, a demanda por trabalho e seu retorno. Isso não foi verificado, conforme sugerem os resultados da tabela, e a estrutura de salários permaneceu bastante estável. Note, no entanto, que os coeficientes do modelo de prêmios com controle são inferiores aos do modelo de prêmios sem controle, o que sugere mudanças na estrutura de características e composição dos trabalhadores por indústria.

Tabela 4

Coeficientes de correlação

\begin{tabular}{cccccccc}
\hline \multicolumn{3}{c}{ Sem } & controle & - modelo 1 & \multicolumn{5}{c}{ Com controle - modelo 3 } \\
\hline Ano & 1996 & 1997 & 1998 & Ano & 1996 & 1997 & 1998 \\
\hline 1996 & 1 & & & 1996 & 1 & & \\
1997 & 0,917 & 1 & & 1997 & 0,805 & 1 & \\
1998 & 0,986 & 0,897 & 1 & 1998 & 0,955 & 0,753 & 1 \\
\hline
\end{tabular}

A tabela 5 reproduz os resultados sobre a estabilidade da estrutura de salários no Brasil de Arbache et alii (2004), em que se utilizou a classificação industrial a 2 dígitos e dados da PNAD das décadas de 1980 e 1990. Os resultados mostram elevadíssima estabilidade dos prêmios salariais, mesmo num período tão conturbado como foram as duas décadas passadas. Essa evidência sugere que a estrutura de salários no Brasil é rígida, e que os prêmios salariais são pouco sensíveis a ciclos, choques e incertezas. De outro lado, fatores como tecnologia e grau de concentração de mercado, por exemplo, parecem ter importância crucial para explicar os salários industriais. 


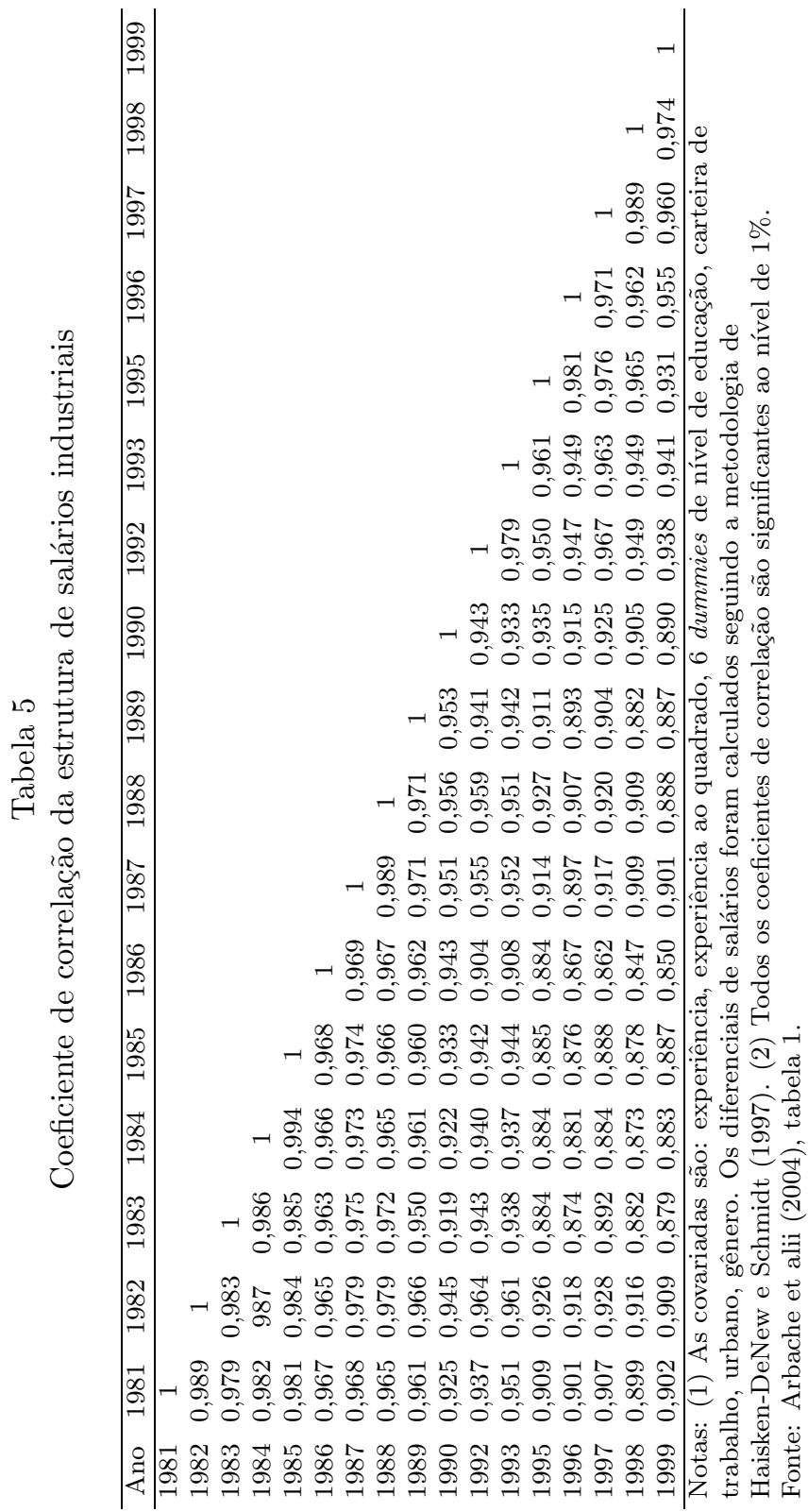




\section{Conclusões}

Este estudo investigou o impacto da filiação industrial no diferencial de salários no Brasil. Diferentemente dos trabalhos anteriores, que investigaram os diferenciais ao nível de 1 ou 2 dígitos, este estudo usou um banco de dados inédito para estimar os prêmios ao nível de 3 dígitos controlando não apenas os atributos individuais, mas, também, as características das firmas nas equações de salário. Dessa forma, identificaram-se de forma muito mais refinada os eventuais efeitos da indústria na formação dos salários.

Os resultados encontrados dão sustentação para a teoria da segmentação e sugerem que a filiação industrial é um importante fator determinante dos salários no Brasil. O estudo também investigou os fatores determinantes dos prêmios salariais industriais e encontrou relação positiva entre escolaridade média, tempo de emprego médio e prêmio salarial industrial. Assim, parece que o capital humano contribui para o aumento do desempenho coletivo, justificando, ao menos parcialmente, a dispersão de prêmios salariais. Logo, o prêmio seria resultado não apenas de segmentação e/ou de rigidezes do mercado, mas, também, de fatores não observáveis.

\section{Referências}

Abowd, J. M., Kramarz, F., \& Margolis, D. N. (1999). High wage workers and high wage firms. Econometrica, 67:251-333.

Abuhadba, M. \& Romaguera, P. (1993). Inter-industrial wage differentials: Evidence from latin american countries. Journal of Development Studies, 30:190205.

Amadeo, E. J. (1994). Bargaining power, mark-up, and wage differentials in Brazil. Cambridge Journal of Economics, 18:313-322.

Arai, M. (1994). An empirical analysis of wage dispersion and efficiency wages. Scandinavian Journal of Economics, 96:31-50.

Arbache, J. S. (1999). A comparison of different estimates of interindustry wage differentials: The case of Brazilian manufacturing. Applied Economics Letters, 6:67-71.

Arbache, J. S. (2001). Wage differentials in Brazil: Theory and evidence. Journal of Development Studies, 38:109-130. 
Arbache, J. S. (2003). Inter-industry wage differentials in Brazil, 1980s-1990s. mimeo, Universidade de Brasília.

Arbache, J. S. \& De Negri, J. (2003). The determinants of Brazilian manufacturing exports. Oxford University. WP CBS 42-2003.

Arbache, J. S., Dickerson, A., \& Green, F. (2004). Assessing the stability of the inter-industry wage structure in the face of radical economic reforms. Economics Letters, 83:149-155.

Bacha, E. \& Taylor, L. (1978). Brazilian income distribution in the 60's: Facts, model results and controversy. Journal of Development Studies, 14:271-297.

Barros, R. P. \& Mendonça, R. S. P. (1995). Uma avaliação da qualidade do emprego no Brasil. Texto para Discussão No. 381, Instituto de Pesquisa Econômica Aplicada.

Blanchflower, D. G., Oswald, A. J., \& Sanfey, P. (1996). Wages, profits, and rent-sharing. Quarterly Journal of Economics, 111:227-251.

Brown, C. \& Medoff, J. (1989). The employer size-wage effect. Journal of Political Economy, 97:1027-1059.

Cacciamali, M. C. \& Freitas, P. S. (1991). Do capital humano ao salário de eficiência: Uma aplicação para analisar os diferenciais de salários em cinco ramos manufatureiros da grande São Paulo. Anais do XIX Encontro Nacional de Economia.

Cowell, F. A., Ferreira, F. H. G., \& Litchfield, J. (1996). Income distribution in Brazil 1981-1990: Parametric and non-parametric approaches. Discussion Paper No. DARP 21, London School of Economics.

Cullen, D. (1956). The interindustry wage structure, 1899-1950. American Economic Review, 46:353-369.

Cunha, P. V. \& Bonelli, R. (1978). Estrutura de salários industriais no Brasil: Um estudo sobre a distribuição de salários médios em 1970. Pesquisa e Planejamento Econômico, 8:95-104.

Da Silva, J. C. (1987). Diferenciação salarial na indústria brasileira. Série Teses 14, Rio de Janeiro: Editora da Fundação Getúlio Vargas. 
Dickens, W. T. \& Katz, L. F. (1987). Inter-industry wage differences and industry characteristics. In Lang, K. \& Leonard, J., editor, Unemployment and the Structure of Labor Markets. Basil Blackwell, Oxford.

DiNardo, J., Fortin, N. M., \& Lemieux, T. (1996). Labor market institutions and the distribution of wages, 1973-1992: A semiparametric approach. Econometrica, 64:1001-44.

Dunlop, J. T. (1957). The task of contemporary wage theory. In Dunlop, J. T., editor, The Theory of Wage Determination. Macmillan, London.

Ferreira, F. H. G. \& Barros, R. P. (1999). The slippery slope: Explaining the increase in extreme poverty in urban Brazil, 1976-96. Country Economics Department Paper Series No. 2210, World Bank.

Fields, G. \& Wan, H. (1989). Wage-setting institutions and economic growth. World Development, 17:1471-1483.

Gatica, J., Mizala, A., \& Romaguera, P. (1991). Estructura salarial y diferencias de salário em la industria brasilena. El Trimestre Econômico, 58:769-792.

Gatica, J., Mizala, A., \& Romaguera, P. (1995). Interindustry wage differentials in Brazil. Economic Development and Cultural Changes, 43:315-331.

Gera, S. \& Grenier, G. (1994). Interindustry wage differentials and efficiency wages: Some canadian evidence. Canadian Journal of Economics, 27:81-100.

Gibbons, R. \& Katz, L. (1992). Does unmeasured ability explain inter-industry wage differentials? Review of Economic Studies, 59:515-535.

Gittleman, M. \& Wolff, E. N. (1993). International comparisons of inter-industry wage differentials. Review of Income and Wealth, 39:295-312.

Groshen, E. L. (1991a). Five reasons why wages vary among employers. Industrial Relations, 30:351-81.

Groshen, E. L. (1991b). Sources of intra-industry wage dispersion: How much do employers matter? Quarterly Journal of Economics, 106:869-884.

Haisken-DeNew, J. P. \& Schmidt, C. M. (1997). Inter-industry and inter-region differentials: Mechanics and interpretation. Review of Economics and Statistics, 79:516-521. 
Hamermesh, D. S. (1980). Commentary. In Siegfried, J., editor, The Economics of Firm Size, Market Structure, and Social Performance. Federal Trade Committee, Washington.

Katz, L. F. \& Summers, L. H. (1989a). Can industry wage differentials justify strategic trade policy? In Feenstra, R. C., editor, Trade Policies for International Competitiveness. University of Chicago Press, Chicago.

Katz, L. F. \& Summers, L. H. (1989b). Industry rents: Evidence and implications. Brookings Papers on Economic Activity, Microeconomics: 209-275.

Keane, M. P. (1993). Individual heterogeneity and interindustry wage differentials. Journal of Human Resources, 28:134-161.

Krueger, A. B. \& Summers, L. H. (1987). Reflections on inter-industry wage structure. In Lang, K. \& Leonard, J., editor, Unemployment and the Structure of Labor Markets. Basil Blackwell, Oxford.

Krueger, A. B. \& Summers, L. H. (1988). Efficiency wages and the inter-industry wage structure. Econometrica, 56:259-193.

Langoni, C. G. (1973). Distribuição de Renda e Crescimento Econômico No Brasil. Editora Expressão e Cultura, Rio de Janeiro.

Lindauer, D. \& Sabot, R. (1983). The Public/Private wage differential in a poor urban economy. Journal of Development Economics, 12:137-152.

Lucas, R. E. (1988). On the mechanics of economic development. Journal of Monetary Economics, 22:3-42.

Lucifora, C. (1993). Inter-industry and occupational wage differentials in Italy. Applied Economics, 25:1113-1124.

Mellow, W. (1982). Employer size and wages. Review of Economics and Statistics, 64:495-501.

Menezes-Filho, N. \& Arbache, J. S. (2003). Trade liberalization, product and labor markets in Brazil. mimeo, Universidade de São Paulo.

Mizala, A. \& Romaguera, P. (1998). Wage differentials and occupational wage premia: Firm-level evidence for Brazil and Chile. Review of Income and Wealth, $2: 239-257$. 
Morrison, A. R. (1994). Are institutions or economic rents responsible for interindustry wage differentials? World Development, 22:355-368.

Murphy, K. M. \& Topel, R. H. (1990). Efficiency wages reconsidered: Theory and evidence. In Weiss, Y. \& Fishelson, G., editors, Advances in Theory and Measurement of Unemployment. Macmillan, London.

Pinheiro, A. C. \& Ramos, L. (1994). Inter-industry wage differentials and earning inequality. Estudios de Economia, 21:79-111.

Reynolds, L. G. (1951). The Structure of Labor Markets: Wages and Labor Mobility in Theory and Practice. Harper and Brothers, New York.

Sarquis, S. J. B. \& Arbache, J. S. (2001). Openess and external effects of human capital. mimeo, London School of Economics.

Slichter, S. (1950). Notes on the structure of wages. Review of Economics and Statistics, 32:80-91.

Souza, P. R. \& Tokman, V. E. (1978). Distribuición del ingreso, pobreza y empleo en areas urbanas. El Trimestre Económico, 45:737-766.

Teal, F. (1996). The size and sources of economic rents in a developing country manufacturing labour market. Economic Journal, 106:963-76.

Wachter, M. L. (1970). Cyclical variation in the interindustry wage structure. Cyclical variation in the interindustry wage structure, 60:75-84.

Weiss, A. (1990). Efficiency Wages - Models of Unemployment, Layoffs and Wage Dispersion. Princeton University Press, Princeton. 


\section{Anexo}

Tabela A.1

Controles da equação de salário - 1998

\begin{tabular}{lcclcc}
\hline Variável & Coeficiente & Teste $t$ & Variável & Coeficiente & Teste $t$ \\
\hline Escolaridade & 0,091 & 1009,00 & Sul & 0,303 & 327,74 \\
Experiência & 0,049 & 609,38 & Sudeste & 0,431 & 517,98 \\
Experiência ao quadrado & $-0,001$ & $-436,70$ & Norte & 0,195 & 114,85 \\
Ocupação 1 (CBO 1) & 0,545 & 184,78 & Centro-Oeste & 0,180 & 124,15 \\
Ocupação 2 (CBO 2) & 0,882 & 450,60 & Firmas exportadoras & 0,128 & 191,59 \\
Ocupação 3 (CBO 3) & 0,063 & 69,90 & Firmas multinacionais & 0,324 & 72,57 \\
Ocupação 4 (CBO 4) & 0,235 & 186,93 & Firmas multinacionais & $-0,121$ & $-26,60$ \\
& & & exportadoras & & 0,071 \\
Ocupação 5 (CBO 5) & $-0,144$ & $-103,29$ & Tamanho 2 & 0,153 & 70,93 \\
Ocupação 6 (CBO 6) & $-0,325$ & $-203,20$ & Tamanho 3 & 0,237 & 111,47 \\
Ocupação 7 (CBO 7) & $-0,068$ & $-91,36$ & Tamanho 4 & 0,311 & 143,95 \\
Ocupação 8 (CBO 8) & $-0,010$ & $-12,81$ & Tamanho 5 & 0,373 & 170,49 \\
Masculino & 0,285 & 457,89 & Tamanho 6 & 0,403 & 186,50 \\
Tempo de emprego na firma & 0,002 & 520,36 & Tamanho 7
\end{tabular}

Obs: Ocupação trata-se da classificação a um dígito da Classificação Brasileira de Ocupações (CBO). A variável tamanho é como segue:

tamanho 1 (firmas com 1 a 10 pessoas ocupadas),

tamanho 2 (firmas com 11 a 50 pessoas ocupadas),

tamanho 3 (firmas com 51 a 100 pessoas ocupadas),

tamanho 4 (firmas com 101 a 250 pessoas ocupadas),

tamanho 5 (firmas com 251 a 500 pessoas ocupadas),

tamanho 6 (firmas com 501 a 1000 pessoas ocupadas),

tamanho 7 (firmas com mais de 1001 pessoas ocupadas). 